\title{
Adolf Behne e a construção do Movimento Moderno - Parte 2
}

\author{
Adolf Behne and the construction of the Modern Movement - Part 2
}

\author{
Maria Isabel Imbronito*, Marcos Mari Barreto**
}

*Professora Doutora, vinculada ao Programa de PósGraduação stricto sensu em Arquitetura e Urbanismo da Universidade São Judas Tadeu (PGAUR/USJT), e à Faculdade de Arquitetura e Urbanismo da Universidade Presbiteriana Mackenzie (FAU/UPM).

ORCID: $\quad 0000-0001-7394$

3809

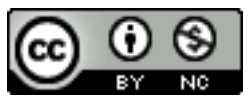

Recebido: 09/02/2020

Aceito: 08/06/2020

https://doi.org/10.37916/arq.urb.v28i.405
**Mestre pelo Programa de Pós-Graduação stricto sensu em Arquitetura e Urbanismo da Universidade São Judas Tadeu (PGAUR/USJT) ORCID:0000-0002-7311 $723 \mathrm{X}$

\section{Resumo}

O livro A Construção Funcional Moderna, escrito por Adolf Behne em 1923, contém discussões fundamentais para a compreensão e condução da Arquitetura Moderna na década de 20 . No livro, o autor identifica algumas correntes de pensamento em curso e as explora em três momentos, determinando os três capítulos de seu livro. No segundo deles, objeto deste texto e tradução, o autor discute os princípios da arquitetura alemã de viés expressionista, cujo desenho específico espelha o estudo detalhado da função. Se a cada necessidade interna resulta uma configuração particular, também se sobrepõem princípios formais oriundos de analogias orgânicas e dinâmicas que estão impregnados no pensamento da época. O autor situa o ponto alto desta vertente na obra de Erich Mendelsohn, e aponta os aspectos negativos da radicalização desta abordagem: ao atender prioritariamente a demandas internas à obra arquitetônica, criam-se edifícios únicos que comprometem a totalidade do conjunto urbano.

Palavras-chave: Arquitetura moderna. História da arquitetura moderna. Teoria da Arquitetura. Erich Mendelsohn. A construção funcional moderna. Expressionismo alemão. Arbeitsrat für Kunst.

\section{Abstract}

Der moderne Zweckbau, book written by Adolf Behne in 1923, presents fundamental discussions for the conduction and understanding of Modern Architecture in the 1920s. In the volume, the author identifies different lines of thoughts, which are explored in three steps that determine three different chapters of the book. Through the second chapter, object of this paper and translation, the author presents some principles of expressionist architecture in German, whose specific design mirrors function. Each internal need results in a particular conformation, to which organic and dynamic analogies were added as formal principles. The author places the high point of this strand in Erich Mendelsohn's work, and points out the negative aspects of the radicalization of that approach: by meeting primarily the internal demands, the unique buildings that were created compromise the urban complex as a hole.

Keywords: Modern Architecture. Modern Architecture History. Architectural Theory. Erich Mendelsohn. The Modern Functional Building. German expressionism. Arbeitsrat für Kunst. 
Este é o segundo, de uma sequência de três artigos, que têm como objeto o livro de Adolf Behne, A Construção Funcional Moderna (1923). Behne foi um teórico alemão de arte e arquitetura que, no início do século $X X$, esteve à frente, juntamente com Walter Gropius e Bruno Taut, do Arbeitsrat für Kunst (AFK), grupo que defendia uma arte integradora do indivíduo e da sociedade. $\mathrm{O}$ autor acompanhou de perto o debate alemão e internacional ao final da década de 1910 e durante a década de 1920, inserindo-se no ambiente que formou e transformou o pensamento moderno nas suas mais variadas vertentes. Seu livro de 1923 traz contribuições sobre os desdobramentos das correntes daquele período, sobretudo acerca do contraponto entre o funcionalismo e o racionalismo.

O livro de Behne está organizado em três capítulos, cada um a ser tratado em artigo separado, que é acompanhado pela tradução de um trecho significativo do texto de Behne referente aos conceitos tratados.
O primeiro capítulo, Não mais fachada, mas edifício, foi assunto no texto Adolf Behne e a Construção do Moderno - Parte 1. Nele, Behne reconstituiu o pensamento, presente na última década do século XIX e na primeira década do século $X X$, que possibilitou a transição da "fachada", elemento estático carregado de princípios formais apriorísticos e desvinculado de relações funcionais, para uma ideia plena e autônoma de "edifício", que equaciona livremente as prerrogativas relacionadas à finalidade para corresponder à dinâmica funcional da vida.

No capítulo seguinte, Não mais edifício, mas espaço conformado, tratado no presente artigo, Behne explora os princípios que levaram o funcionalismo acentuado a afastar-se do "edifício" convencional em direção a uma construção peculiarmente moldada pelo atendimento à função. Ao final do capítulo, Behne identifica dois aspectos presentes na arquitetura associada ao organismo funcional: a individualidade da obra e a ideia de movimento, para depois discutir os impasses da abordagem funcionalista frente ao caminho tomado pelo racionalismo moderno. 
No terceiro capítulo, Não mais espaço conformado, mas realidade configurada, a ser tratado no texto Adolf Behne e a Construção do Movimento Moderno - Parte 3, Behne contrapõe o organismo conformado apresentado no capítulo 2 à arquitetura moderna que avança na direção de princípios extensivos, contrapondo o edifício específico do funcionalismo orgânico às propostas do racionalismo abstrato, que respondem a finalidades menos precisas, mas apresentam maior capacidade de orquestração da configuração conjuntiva. Para o teórico, desde a formulação do edifício autônomo, passando pelo organismo conformado até a sistematização da totalidade do espaço construído, a arquitetura torna-se "extraestética", ou seja, cada vez mais transparente à vida e integrada a ela.

Construção Funcional Moderna, parte 2: organismo conformado

O segundo capítulo do livro A construção funcional moderna é dedicado ao funcionalismo tal como ocorreu na Alemanha, que nos remete à arquitetura do Expressionismo. $\mathrm{O}$ autor, ligado a artistas dessa vertente, traça nesse capítulo um panorama consistente de arquitetos e obras, atendose à posição assumida por tais arquitetos quanto ao propósito da arquitetura em responder a prerrogativas muito concretas do ponto de vista funcional, mas que ambiciona, do ponto de vista artístico, superar sua mera equação.
É importante comentar que o espectro de arquitetos compreendido neste capítulo funde categorias da historiografia, ao considerar, ao lado de arquitetos que se posicionaram pela Kunstwollen, arquitetos que, à época do texto, já se direcionavam pela objetividade, como Walter Gropius. Vale dizer que o autor poucas vezes utiliza o termo Expressionismo. Para estipular as origens de um funcionalismo orgânico de viés expressionista que produzirá o organismo conformado - tipo original sobre o qual Behne pretende discorrer -, o autor retoma o legado de Henry Van de Velde. Contudo, as manifestações maduras deste funcionalismo, que Behne identifica nas fábricas de Erich Mendelsohn, representam já um possível ponto de contato do expressionismo alemão com o pensamento racionalista, em um ponto de transição que se nota na obra de arquitetos como Luckhardt e Gropius.

O autor desenvolve o capítulo 2 de seu livro abordando a seguinte sequência de arquitetos: Walter Gropius (1883-1969) e Peter Behrens (1868-1940) para introduzir a lógica e estética funcionais a partir do edifício industrial; Henry Van de Velde (18631957), para afastar-se da ideia de "edifício" em direção a de "organismo", e introduzir uma certa concepção de movimento na obra arquitetônica; Hans Poelzig (1969-1936), Hermann Finsterlin (18871973) e Erich Mendelsohn (1887-1953), para explicar o pensamento e os princípios relacionados ao edifício funcional de viés expressionista. Inseridos na mesma linha de pensamento estariam também 


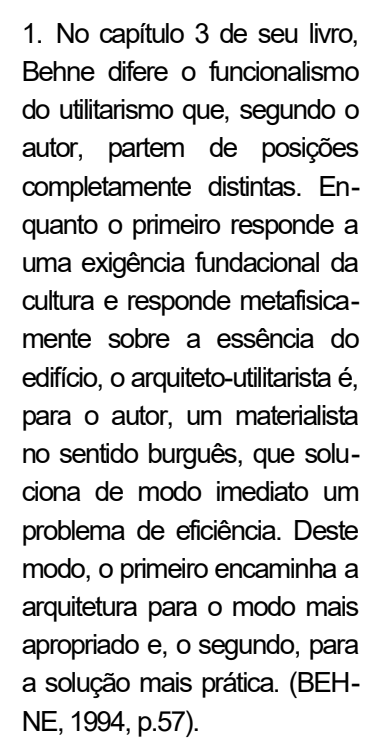

usjt • arq.urb • número 28 | maio-agosto de 2020
Hugo Häring (1882-1958), Hans Scharoun (18931972) e Adolf Räding (1888-1957), arquitetos citados apenas no capítulo 3 do livro de Behne, que foram utilizados pelo autor para estabelecer o contraponto entre a consolidação do pensamento funcionalista alemão e o racionalismo abstrato em ascensão, tanto na Holanda e como através de Le Corbusier. Como parte importante do conteúdo relacionado ao funcionalismo está localizado no terceiro capítulo do livro, nossa discussão e recorte neste artigo considera tais trechos sem, contudo, antecipar a questão principal a ser discutida no capítulo 3, relacionada ao racionalismo e aos processos de sistematização do projeto moderno.

\section{Do atendimento à função ao edifício-organis-} mo

norte-americanos referentes à eficiência do espaço hospitalar e industrial fordista, ressaltando a consciência da justa posição e medida para o funcionamento adequado dos processos dentro das construções "utilitárias".

Os exemplos utilizados por Behne prestam-se a romper as amarras do pré-julgamento artístico e conferir à arte a liberdade necessária para atingir um novo status.

Ao ordenarem-se as partes de uma construção em razão de sua utilidade, ao aparecer um espaço vital em lugar de um espaço estético - e uma tal ordem que designamos como dinâmica - a construção se desfaz das cadeias da velha ordem, rígida e estática, dos eixos e das simetrias, e se situa em novo princípio. Em vez de um equilíbrio estreito, material, estável (simetria), aparece um equilíbrio novo, mais audaz, lábil, em que se contrapesam tensões cruzadas, que correspondem melhor à nossa essência (polaridade): com isso, aparece uma configuração inteiramente nova e viva, livre de inibições e dissimulações. A construção, mediante sua adequação à função, consegue então uma maior e melhor unidade interna, torna-se mais orgânica; ao abandonar as velhas convenções e formalismos da representação, a materialização de uma configuração necessária faz desaparecer também toda classe de lastros e inibições. (BEHNE, 1994, p.54, tradução nossa).

cânica - de instrumentos, tubos, circulações, etc. -, mas, sobretudo, para o funcionamento integral de partes especializadas que, em seu conjunto, compõem estruturas dinâmicas de funcionamento, força e movimento. Behne perpassa os princípios
Neste novo contexto, porém, a arquitetura não pode ser considerada mero rebatimento da função e restringir-se ao utilitarismo. Behne é claro ao afirmar 
(...) o efeito libertador que o estudo das construções utilitárias americanas exerceu em Gropius fica claro em Alfeld [na Fábrica Fagus], e fica igualmente claro que Gropius procede, não obstante, a um filtro estético sobre a imediatez americana. (Behne, 1994, p.45, tradução nossa).

Após utilizar o atendimento à finalidade como gatiIho para desmontar regras formais ideias e comentar sobre as restrições que decorrem do simples rebatimento utilitarista da forma, Behne vai atrás do pensamento que pretende construir a arte de um novo tempo sobre as novas bases. Retorna ao antecessor de Gropius, Peter Behrens, arquiteto alemão pioneiro em projetar para a indústria, sintonizado com o debate do Werkbund alemão na relação entre a dimensão artística e os processos industriais. Segundo Behne, Behrens reclamava por soluções típicas que corresponderiam à época moderna. Behne transcreve uma fala de Behrens para a revista Plakat (1920), sobre os edifícios que projetou para a AEG na década de 10:

Nos trabalhos de formalização de qualquer estabelecimento industrial, se trata sempre de extrair o caráter a partir da essência da coisa que se está configurando, de aprofundar o típico: qualquer obra de arte dos tempos passados segue evidenciando sua augusta grandeza frente ao olhar retrospectivo que se lhe dirige, em sua condição de resposta típica ao objetivo correspondente. (Behrens apud Behne, 1994, p.41, tradução nossa).
Apesar de, teoricamente, exaltar a importância do tipo, Behne sustenta que persiste em Behrens, paralelamente, o objetivo de alcançar a forma artística que garanta ao edifício e ao produto industrial um significado e um valor representativos da cultura moderna e do valor da indústria. Behrens estaria assim afastado da objetividade industrial americana e, se avança sob vários aspectos em direção ao edifício típico, não se desprende do "conceito" de edifício enquanto arquitetura com importância artística, histórica e representativa. $\mathrm{O}$ autor aponta também que o resultado alcançado por Behrens permanece preso aos elementos construtivos que determinam, historicamente, o campo da arquitetura, pois "subsiste em Behrens uma dualidade: a satisfação correta da finalidade, e sua redução a um volume convencional: parede, teto, janela..." (BEHNE, 1994, p.43, tradução nossa), o que resultaria em obras estereométricas e culturalmente reconhecíveis.

Para o autor, a Fábrica de Turbinas da AEG (1909) marca uma exceção neste modo de conceber arquitetura, pois nela Peter Behrens atingiu um espaço novo, no qual o esforço configurador está plenamente concentrado na organização geral do edifício, no atendimento à finalidade e na utilização de novos materiais. Segundo Behne, é no galpão dos grandes motores da AEG que Behrens baniu o revestimento, o ornamento e qualquer recurso formal, pois ali "o construído era forma, não necessitava de formas" (BEHNE, 1994, p.43, grifo nosso). A constituição do edifício congrega a tectônica direta e a orga- 
nização da fábrica: a estrutura principal conformase num desenho de pórtico articulado que expõe o material, libera a nave para os arranjos lineares da produção, sustenta a ponte rolante, permite a iluminação plena com vidros no fechamento lateral e de teto, enquanto um corpo lateral, justaposto à nave na seção transversal, com mais pavimentos de menor pé direito, concentra as atividades de apoio à produção.

Contudo, segundo Behne, Behrens retoma fórmulas clássicas em obras posteriores, que neutralizam a função e a finalidade sob uma ordem inalterável que renuncia, inclusive, à expressão advinda dos novos enfrentamentos. Neste retrocesso, o "edifício" volta a afirma-se enquanto construção cultural e histórica e reafirma o papel da representação na arquitetura.

Já a Fábrica Fagus (1911-1925) de Walter Gropius é, para o autor, a primeira obra não "construída" mas "materializada" em aço, concreto e vidro. Behne segue dizendo que se nota em Gropius o efeito libertador do estudo das construções utilitárias americanas. Contudo, mesmo rejeitando qualquer formalismo, o filtro estético de Gropius impede a imediatez e a simplificação banal da obra. Nesse ponto, o autor alinha uma citação precisa de Jean Cocteau para Le coq et l'arlequin manomètre (n.4, 1923) sobre a recusa do mero rebatimento utilitário:
As máquinas e as construções americanas parecem tanto com a arte grega que a utilidade lhes confere uma secura e grandeza despojadas do supérfluo. Mas arte não é isso. O papel da arte consiste em compreender o sentido da época e extrair dessa secura prática um antídoto contra a beleza do inútil que fomenta o supérfluo. (Cocteau apud Behne, 1994, p.45-46, tradução nossa)

Behne estende sua argumentação a dois contemporâneos de Behrens (1868-1940) que buscam estabelecer a correspondência entre forma e função e que, ao se debruçarem sobre novos princípios da arte, se mostram libertos do formalismo classicizante: Frank Lloyd Wright (1867-1959) e Henry Van de Velde (1863-1957). Interessado em diferenciar Van de Velde de Wright, Behne traça um comparativo entre ambos, e as diferenças que encontra constroem justamente a passagem do "edifício" autônomo de Wright para a ideia de "organismo conformado". Com Wright, no primeiro capítulo do livro $A$ Construção Funcional Moderna, Behne introduziu o conceito de edifício enquanto livre articulação espacial resultante da ação conformadora do arquiteto em resposta à finalidade; já Van de Velde irá contribuir para transformar o edifício em uma forma espacialmente moldada pela função, pelo material e pela ideia de movimento.

O principal parâmetro para a leitura comparativa que Behne estabelece entre Wright e Van de Velde é o "movimento", que desempenha um papel chave para a compreensão dessas arquiteturas na relação entre autor, obra e vontade artística. Existe nos dois 
arquitetos analisados a preocupação de que o edifício corresponda à vida de modo direto e em todas as suas nuances e dinâmicas. Deste modo, um edifício funcional estático e rígido é, de partida, um edifício impróprio, incapaz de corresponder ou assimilar as transformações do mundo - natural ou mecânico.

Behne considera que o movimento, em Wright, reforça a ideia do edifício enquanto matéria estruturada e submetida a um firme princípio organizativo com forte concepção autoral. Segundo Behne, o movimento na obra de Wright entabula "de modo consequente e consciente" a relação entre o espaço em planta e a expansão do volume tridimensional (BEHNE, 1994, p.46). Apesar dos elementos horizontais e verticais utilizados neste processo serem peças estáticas, a relação que estabelecem entre si é de soltura e tensão, e o sentido de movimento obtido decorre daquilo que o autor chama de manipulação "externa" destes elementos, ou seja, resulta da vontade e da razão do arquiteto que opera a forma.

Já para Van de Velde, conforme nos faz ver Behne, o movimento "tem um sentido literal, como uma força que organiza a construção desde o interior até o exterior." (BEHNE, 1994, p.46, tradução nossa). Na posição defendida por Van de Velde, o arquiteto lida com forças intrínsecas ao edifício para obter "formas eloquentes", que não traduzem a simples vontade humana, mas a vontade da coisa em si, "vontade da objetividade, da função, dos materiais, e que se materializa a si mesma em um processo no qual o homem é somente mediador." (BEHNE, 1994, p.46, tradução nossa).

Enquanto em Wright o papel da vontade ordenadora resguarda a existência do "edifício" enquanto elemento autônomo, tridimensional e articulado - tal como Behne o descreve no capítulo 1 -, em Van de Velde, o funcionalismo com resquícios românticos faz do edifício um "organismo livre e instituído de maneira inteiramente nova", sob ação de forças poderosas que degradam seus limites e chegam a uma "forma em evolução", que se paralisa em um corpo dramático. A ideia de movimento é transposta em analogias literais à forma do edifício, com prejuízo da ortogonalidade e da verticalidade que acompanharam historicamente a arquitetura. Behne defende ainda um outro aspecto na origem da forma vandeveldiana: Van de Velde argumenta por uma relação causal entre a genealogia da forma e uma aptidão do material e da técnica empregados, e sustenta que a forma assumirá uma expressão que é, também, oriunda da tectônica. Ou seja, Van de Velde procurar imprimir à forma um "sentido" construtivo de origem que lhe justifique. Desse modo, Van de Velde interpreta que a solução formal se desdobra de pré-disposições tanto construtivas como funcionais, que são intrínsecas ao próprio objeto em formação. (BEHNE, 1994, p.48). 
Autores posteriores aprofundariam as críticas a esta relação entre a expressão idiossincrática do artista e seu papel transparente enquanto agente mediador de uma força configurativa inerente ao material, à finalidade ou interna ao próprio objeto. Contudo, são muitos os indícios e depoimentos de época que sustentam que o pensamento funcionalista mergulha a fundo na configuração advinda da finalidade, rebaixando o papel do arquiteto a uma ação que meramente traduza estas forças ao viabilizar a forma arquitetônica definitiva. Assim, o gesto do artista, materializado e tornado visível em Van de Velde, transfigura uma vontade maior que a do próprio artista. Van de Velde, contudo, apesar de situar a ação do arquiteto em meio a uma conjuntura de forças atuantes, é forte defensor da individualidade da solução atingida frente à normalização proveniente da produção mecânica, o que implica, como resultado, em edifícios únicos. Este é um ponto importante a ser destacado para seguirmos as considerações de Behne até o capítulo 3.

Vale lembrar que a postura do arquiteto transparente está, de outro modo, presente e radicalizada também nas vertentes racionalistas e utópicas da década de 1920, e alguns movimentos do início do século $X X$ enveredam pela ideia da extinção da arte e arquitetura enquanto expressão individual do artista, reforçando seu papel perante o corpo social. Segundo Colquhoun (2004, p.31), esta posição nas vanguardas históricas é um desdobramento do determinismo histórico hegeliano, que posiciona a
História no comando do movimento em direção ao futuro e transforma $\mathrm{o}$ arquiteto em agente, neste caso, da vontade histórica, abdicando de seu papel de artista.

\section{Organismo conformado: de Finsterlin a Men- delsohn}

Somam-se à difusão das ideias de Van de Velde e à grande influência que tiveram na Alemanha a presença de outras referências que se fortaleceram naquele país durante a década de 1910. Frampton relata o surgimento de movimentos protoexpressionistas em torno do poeta Paul Scheerbart e a fricção que se desenvolve entre a posição oficial do Werkbund alemão e a corrente que se posiciona pela Kunstwollen (FRAMPTON, 2008, p.139). Bruno Taut e Adolf Behne, com a participação de diversos arquitetos, conduziram a Arbeitrat für Kunst (AFK), liga pela valorização das artes e ofícios que teve breve duração. A partir de Taut e sua revista Frühli$c h$, difundiu-se o pensamento por uma arte expressiva e originária do povo, que foi expresso nas correspondências trocadas na chamada Corrente de Cristal.

Do ponto de vista do corpo social, compunha o imaginário do Arbeitrat für Kunst o resgate de manifestações que fossem socialmente representativas e orgânicas, como a catedral medieval, atualizada e multiplicada nas propostas que constituem variantes da Stadtkrone de Taut (também presente em pro- 


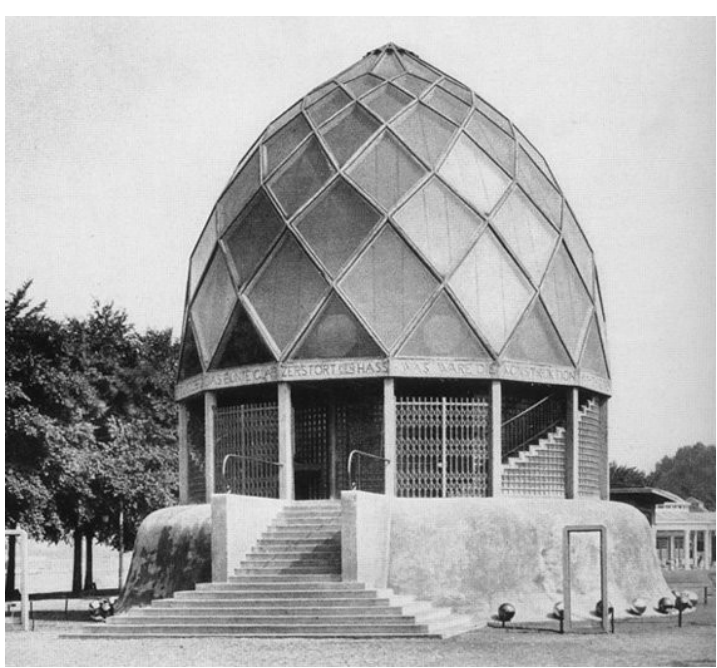

Figura 1. Bruno Taut, Pavilhão de Vidro na exposição do Werkbund, Colônia, 1914. Exemplar inspirado na ideia de Stadtkrone, coroa da cidade. Disponível em: https:// upload.wikimedia.org/wikipedia/commons/e/ed/ Taut_Glass_Pavilion_exterior_1914.jpg Acesso em 23/11/2019.

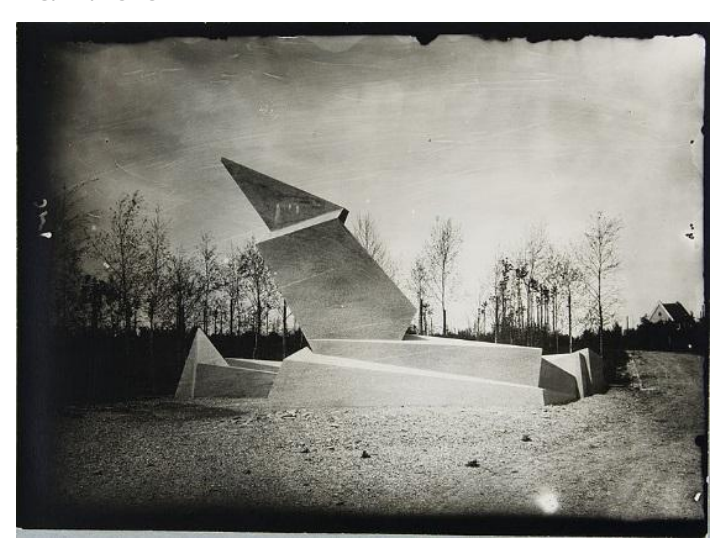

Figura 2. Walter Gropius. Denkmal für die Märzgefallenen (Monumento aos mortos de março), Weimar, 1921. Disponível em: https:// commons.wikimedia.org/wiki/

File:Monument_to_the_March_dead.jpg . Acesso em 23/11/2019. postas de Luckhardt, Poelzig, e levada à gravura inaugural da Bauhaus feita por Feininger, em 1919). Combinadas com a abordagem funcional, difundiram-se as analogias com cristais, que resultaram em estruturas espaciais complexas, e analogias com organismos, que resultaram em formas fisionômicas. Percebe-se que as arquiteturas propostas estão sensivelmente pautadas por este conjunto de valores presente no contexto artístico alemão, e carregam um caráter representativo da sociedade, além de meramente lançarem-se ao atendimento direto à função que, entretanto, persiste enquanto argumento válido dentro da arquitetura expressionista.

Em busca da superação do "edifício" historicamente sedimentado, Behne aborda obras da arquitetura alemã nas quais um novo princípio é desencadeado no interior da relação função-espaço. $O$ salto identificado por Behne equivale a abrir mão do tipo "edifício" conforme se fez presente na cultura arquitetônica, reforçado ao longo dos séculos em suas ortogonalidades, técnicas construtivas e arranjos em planta, para enveredar por um caminho que se distancia dessa herança e resulta em corpos cuja forma se aproxima do estilhaçamento, da geometria rochosa ou da massa tortuosa dos organismos.

Behne ilustra essa passagem com desenhos e esboços de edifícios feitos por Hermann Finsterlin que investiga as formas de uma arquitetura fisionô mica. Para Finsterlin, a forma orgânica do mundo encontra-se "entre o cristal e o amorfo". Um texto publicado na revista Frühlich n.2 permite identificar a combinação destas duas referências.

No espaço interior da nova casa, o homem não se sentirá tão só ocupante de um fabuloso cristal, mas propriamente um habitante de um organismo, que circula de órgão em órgão, que dá e recebe em simbiose com um gigantesco útero materno fossilizado. A sucessão cidade-casa-móvelvasilha constitui um pequeno fragmento da estrutura complexa na qual se traduzem as formas do mundo; seus elementos crescem uns a partir dos outros, tal como as gônadas de um organismo. Estas criaturas ocas devem deixar de ser, umas a respeito das outras, corpos estranhos e distanciados. Dizei-me se o esquema tão violento de vossas seis paredes nunca vos há irritado, se não é um caixão que aprisiona vossas mil necessidades; se nunca vos tomou de assalto o desejo secreto de mudar o lugar, seguindo o ritmo de vossos espíritos cansados. (FINSTERLIN apud BEHNE, 1994, p.48, extraído de revista Frühlich n.2, p.36, tradução nossa a partir da versão em espanhol).

Behne afirma que a Torre Einstein de Erich Mendelsohn em Postdam (1920/21) é uma arquitetura tributária tanto de Finsterlin como de Van de Velde. Do primeiro, aproxima-se pelo corpo tortuoso. Do segundo, pela ideia de movimento. Para Frampton, a Torre ecoa também as ideias de Bruno Taut, e o observatório conforma-se no topo como uma coroa (2008, p.143). 


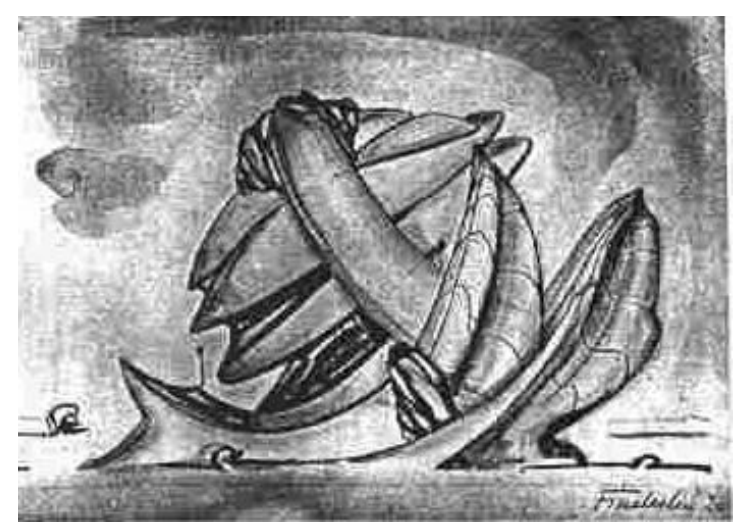

Figura 3. Herman Finsterlin. Casa de vidro, 1924. Publicada na revista Formspiel. Disponível em: https:/tcommons.wikimedia.org/wiki/

File:House_of_glass,_Finsterlin,_1924.jpg Acesso em 23/11/2019.

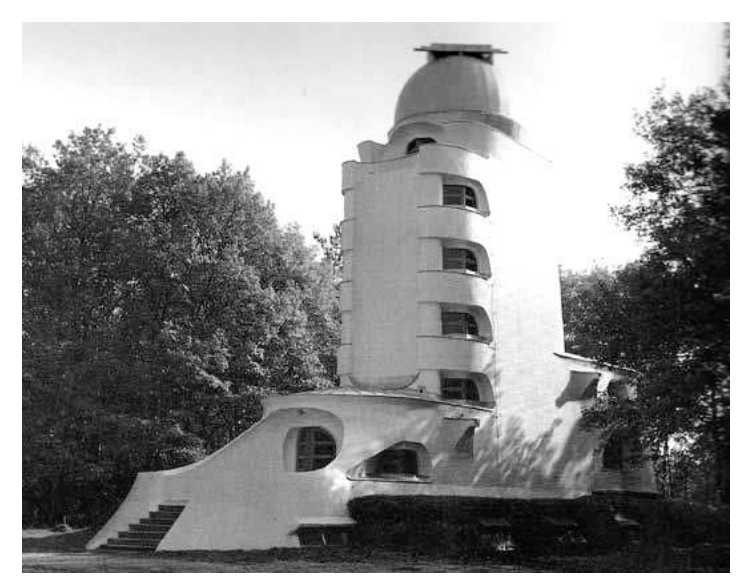

Figura 4. Erich Mendelson. Torre Einstein, Potsdam, 1920-21. Disponível em: https://upload.wikimedia.org/ wikipedia/commons/8/80/Torre_Einstein\%2C_Potsdam

\%2C_Alemanha\%2C_1920.jpg Acesso em 23/11/2019.
Behne identifica os excessos que o desdobramento da arquitetura expressionista alemã poderia assumir, apontando para a crítica holandesa de J.F. Staal ao falar da Torre Einstein, de Mendelsohn: "é o melhor da Alemanha e é um dos melhores trabaIhos pessoais, mas é demasiado alemão e demasiado pessoal" (STAAL apud BEHNE, 1994, p.50, tradução nossa). Isso revela o valor do funcionalismo alemão pela individualidade da solução arquitetônica e por seu papel de relativizar os princípios sistemáticos do racionalismo moderno. Também abre caminho para a crítica feita a esta vertente no terceiro capítulo do livro A Construção Funcional Moderna, em que Behne discute o caminho adotado pelo racionalismo abstrato e as vantagens deste no enfrentamento do projeto expansível moderno.

Ao final do capítulo 2 de seu livro, Behne fala sobre um equilíbrio razoável encontrado pela vertente funcionalista por volta do período em que escreve o livro. Esta parte do texto é bastante significativa, pois revela a sensibilidade racionalista que gradualmente se introduziu no pensamento do grupo $\mathrm{AFK}$, inicialmente oposto à produção extensiva mecanizada e defensor de uma arte do povo. Esta mudança de pensamento vai assegurar a prevalência do racionalismo na arquitetura moderna e marcar a virada do pensamento alemão. Frampton (2008, p.141-142) ressalta a participação de Hans Luckhardt, integrante do AFK, no redirecionamento do grupo quando escreveu, em 1920, que não era mais possível ignorar os princípios tayloristas da época, como também não era possível provar que estes fossem hostis à arte. É nessa mesma circunstância que Walter Gropius, outro ex-integrante do AFK, questiona, nos primeiros anos da Bauhaus (de 1919 até 1922-23), sua posição anterior, perante a necessidade do surgimento de um desenho voltado para a indústria. O próprio Adolf Behne, originalmente integrante e fundador do mesmo grupo, torna-se amigo pessoal de Theo van Doesburg, e dedica o terceiro capítulo de seu livro de 1923 ao pensamento racionalista holandês. Quanto a Mendelsohn, é sabido que uma viagem à Holanda o colocou frente à polêmica entre o Wendingen e o De Stijl, onde possivelmente reconheceu um cenário de enfrentamento parecido ao que se delineava na Alemanha.

O ponto de equilíbrio da arquitetura funcionalista, valorizado por Behne, é exemplificado através dos projetos de fábricas que Mendelsohn construiu no início dos anos 1920 (Fábrica de Chapéus em Lauckenwalde, 1921-23, fábrica têxtil em Wüstegeirsdorf, 1922-23). O conjunto das obras de Mendelsohn revela a acentuação geométrica dos volumes aliada a uma crescente preocupação com a coerência construtiva entre forma e técnica. Preocupações semeIhantes também estão presentes em Hugo Häring (Granja Garkau, Mecklenburg, 1924) e Hans e Wassily Luckhardt (Concurso para a Fábrica Norma, Berlin, 1923). Em Mendelsohn, a ideia de movimento da obra aproxima-se de Van de Velde: o movimento surge em conformidade com a vocação 


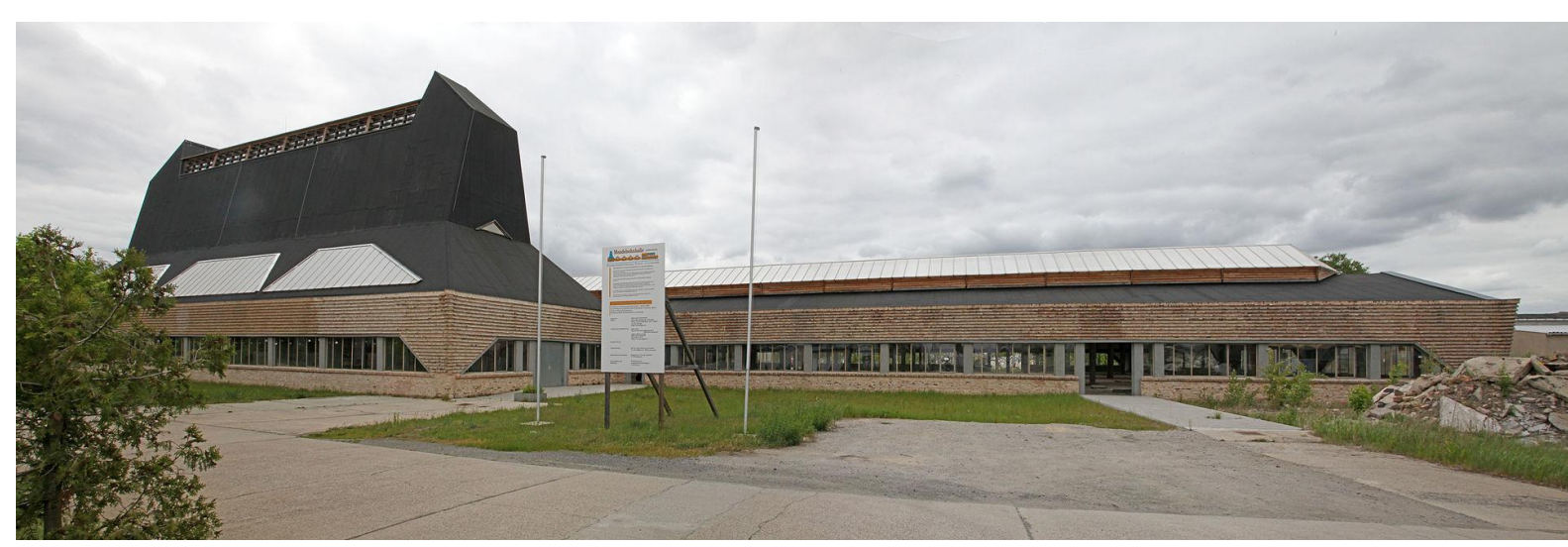

Figura 5. Erich Mendelson. Fábrica de Chapéus, Luckenwalde, 1921-23. Disponível em: https://upload.wikimedia.org/ wikipedia/commons/7/7f/Hutfabrik_Friedrich_Steinberg_Herrmann_\%26_Co.jpg Acesso em 23/11/2019.

do material empregado e conduz ou explicita a função, tanto dos espaços de uso como dos fluxos e do entorno.

Para o teórico alemão, em obras como a Fábrica de Chapéus em Luckenwalde (Mendelsohn, 192123), "o tipo edifício - paredes verticais, cobertura, janelas - resulta superado em benefício do espaço conformado" (BEHNE, 1994, p.51). No conjunto da fábrica, a adequação funcional não corresponde apenas às dinâmicas dos espaços internos, mas é estendida à tectônica: Mendelsohn pretende, como Van de Velde, realizar a busca de um "sentido" construtivo. Os edifícios da fábrica remetem, ao mesmo tempo, ao orgânico e ao cristal explorados por Finsterlin. Com o advento do concreto armado, a construção transforma-se em um edifício-corpo cuja estrutura conforma verdadeiros arcabouços ósseos, cavidades plenas e inundadas de luz. A estrutura flexiona-se, na sucessão de naves internas, para tocar o solo, conferindo amplitude e transparência ao espaço que remete a estruturas metálicas como a Galeria das Máquinas (Dutert, Contamin, 1889), ou ao Matadouro de Lion (Tony Garnier, 1915), mas também a alguns edifícios de concreto armado de Auguste e Gustave Perret. Se a fábrica de Mendelsohn dá sentido à fala de Van de Velde na analogia da estrutura com os ossos do corpo, também o faz em suas geometrias angulosas quanto à arquitetura de Finsterlin, na constituição de angulações presentes nas fiadas e quinas dos muros de tijolos em encontro com a angulação da cobertura e com as aberturas, analogia que se acentua na pronunciada cobertura do galpão principal de acesso à fábrica.

O pensamento alemão, como se vê, levou a arquitetura na segunda década do século $X X$ a arquiteturas singulares marcadas por exemplares únicos. A função continuaria a cumprir seu papel condicionador da configuração da forma, uma vez que a arquitetura, agora um organismo totalmente moldável, absorve a variação funcional implicada ao espaço e conforma-se em função dos fluxos e das finalidades. $\mathrm{O}$ aspecto de dinamismo e movimento encobre, contudo, uma importante questão: a coordenação da forma implica, por princípio, na estabilização da função e sua fixação em uma forma definitiva. $O$ edifício assim pensado não permanece aberto a novas perspectivas funcionais em função da transformação no tempo. A questão, percebida por Behne, 
será comentada e debatida em profundidade no terceiro texto desta série.

\section{Nicht mehr Haus / sondern geformter Raum}

Wir hatten bereits bei Wright vom Element der "Bewegung" gesprochen. Bei van de Velde handelt es sich um etwas wesentlich anderes. Der Unterschied ist der zwischen einem nüchtern sachlichen Amerikaner und einem romantischen Europäer; denn ein Romantiker steckt in van de Velde - neben einem Rationalisten.

Wrights "Bewegung" ist eine konsequentere und bewußtere Ergreifung des Raumes - im Grundriß und ein strafferes Spannungsverhältnis der Bauteile zueinander - im Aufriß. Die Bauteile selbst sind absolut "ausdruckslos", sind selbst unbewegt, technisch bestimmte, normungsfähige, fertige Stücke. Die Bewegung wirkt als eine von außen kommende mechanische Kraft. Ein Menschenwille hat mit Hilfe der Maschine das Haus ausnfertigen Stücken winkelig-eckig konstruiert.

Van de Velde nimmt Bewegung in einem wörtlicheren Sinne als eine den Bau von innen her plastisch organisierende Kraft. Er kommt zu Kurven und Schwingungen, kommt zu Formen, die immer nur das eine Mal wahr sein können, $d$. h. nur in diesem einen Zusammenhang Geltung haben. Er kommt zu sprechenden, ausdrucksvollen Formen. Es sollnicht der als begrenzt empfundene Menschenwille der das Werk bestimmt und festlegt, sondern der Wille der Sachlichkeiten, der Zwecke, der Materialien soll sich selbst verwirklichen - wobei dann der Mensch mehr der Vermittler ist. Van de Velde übt ein Sich-Einfühlen in die Funktionen und kommt von hier aus zu einem formalen Ausdruck der Bewegung, der bei Wright durchaus vermieden ist. Die Auffassung van de Veldes ist eine Parallele zum etwas später einsetzenden malerischen Expressionismus.

Funktion - Bewegung - weiterhin Ausdruck - Symbolik - Romantik - Individualismus - und schließlich Anthropomorphismus liegen logisch dicht beieinander, d. h. der Einfluß van de Veldes war wichtig und wertvoll, aber nicht durchaus unbedenklich. Er enthielt auch eine Gefahr.

Bei Wrights Auffassung konnte der Typ "Haus" trotz aller Neuerungen und Verbesserungen bestehen bleiben. Die Eindeutigkeit, Klarheit und Bestimmtheit seiner Kanten begrenzte einen Raum, den menschlicher Wille sich unterworfen und geordnet hat.

Bei van de Veldes Auffassung verwischen sich leicht die Grenzen. Das Ergebnis der sich selbst in starken Kurven und Schwüngen verwirklichenden, frei gegebenen Kräfte könnte sehr wohl den Kasten zerschlagen und einen völlig anders gearteten, freien Organismus an seine Stelle treten lassen - ein Beispiel im kleinen: der Schreibtisch Osthaus. 
Die Häuser van de Veldes (Esche und Körner in Chemnitz, Hohenhof und Springmann in Hagen in Westfalen, Dürckheim und Henneberg in Weimar und Schulenburg in Gera) lassen eine Auflösung des Hausbegriffes nicht erkennen, und sie zeigen deshalb nichts von einer Auflösung - am ehesten noch das Haus des Arztes Dr. Leuring in Scheveningen -, weil der Romantiker van de Velde zugleich ein Konstrukteur ist. Als solcher verläßt er den Typ des Hauses nur dort, wo es sachlich geboten ist - beim Bau der Weimarer Kunstschule oder beim Bau des Kölner Werkbundtheaters, das ohne einleuchtenden Grund leider abgerissen worden ist. In diesen beiden Bauten zeigt sich, wie wertvoll die Auffassung der Bewegung im Sinne van de Veldes für eine Erneuerung des Baukörpers sein kann trotz mancher auch hier noch vorhandenen Nachklänge des Jugendstiles.

Wollen wir freilich sehen, bis zu welcher letzten Konsequenz ein romantisch-pantheistisch gefärbter Funktionalismus führt, so betrachten wir am besten die Entwürfe Hermann Finsterlins - die denkbar radikalste Auflösung des Hausbegriffes, die Annäherung des Hauses an Formen der organischen, der wachsenden Natur.

Der Formtypus der letzten größten genialen Erfindung des Erdgeistes, die Form des Organischen, liegt zwischen dem Kristall und der Amorphe. Auf diesem Mittelüberweg sprießt auch meine Architektur. Im Innenraum des neuen Hauses wird man sich nicht nur als Insasse einer märchenhaften Kristalldrüse fühlen, sondern als interner Bewohner eines Organismus, wandernd von Organ zu Organ, ein gebender und empfangender Symbiote eines fossilen Riesenmutterleibes. Ein kleines Bruchstück aus dem translatorischen Schachtelsatz der Weltformen liegt in der Folge von Stadt, Haus, Möbel und Gefäß; eines aus dem andern wachsend wie die Gonaden eines Organismus müssen diese Hohlgeschöpfe nicht verlagerte Fremdkörper sein wie bisher. Sagt mir, ob euch nie das gewalttätige Schema eurer sechs Wände irritiert und die injizierten Sachsärge eurer tausend Notwendigkeiten - ob nie die geheimnisvolle Lust an euch herankroch, euch zu umräumen nach dem Rhythmus eurer atmenden Seele? (Frühlicht, Heft 2, S. 36.)

Finsterlin, der seine Entwürfe als "Seelengletschermühlensysteme" bezeichnet, ist hemmungsloser Romantiker. Van de Velde ist nicht nur Romantiker, er ist zugleich Rationalist. Der Romantiker van de Velde gehört so wenig wie Finsterlin zur Gattung der retrospektiv eingestellten - und der Rationalist ist mit Betonung ein Mensch unserer Zeit.

Nichts ist häßlich in der Welt der technischen Erfindungen, der Maschine und der tausend $\mathrm{Ge}$ brauchsgegenstände, die ebenso wichtigen Zwecken dienen wie Architektur und Kunstgewerbe. Ja, ihre durch Wahrheit und Kühnheit erschütternden Formen haben alle jene, die der neuen, der zukünftigen Schönheit leidenschaftlich entgegenharrten, zu Ausdrücken höchster Bewunderung hingerissen. (Die drei Sünden wider die Schönheit, S. 41.) 
Was diejenigen, welche diese Prinzipien bekämpfen, am meisten zu genieren scheint, ist die Tatsache, daß es gerade Prinzipien sind und daß diese außerdem noch eine geistige Anstrengung erfordern, an die sie nicht mehr gewohnt sind... Sind wir am Ende der Welt oder ist diese in die Sackgasse des trockensten Puritanismus geraten, weil wir uns auf eine formelle und einfache Regel der Konstruktion berufen, in welcher ich wohl den geheimen Zug unseleer Zeit entdecke, welche, nachdem sie alles kontrolliert hat, sich nur noch mit den Sachen begnügt - einerlei auf welchem Gebiete -, welche inr nach diesem Examen noch vernünftig, mächtig und fähig erscheinen, anderes, noch Vernünftigeres und Mächtigeres nach sich zu ziehen? (Innendekoration, November 1902)

Die Brücke zwischen dem Romantiker van de Velde und dem Rationalisten van de Velde schlägt die Konstruktion. Van de Velde erläutert die Form seiner Säule im Vestibül des Folkwang-Museums und sagt zusammenfassend: "Ihre Form zeigt ihre Seele oder, wenn man genauer will, ihre Knochen." (Innendekoration, Oktober-November, 1902)

Auf der Suche nach der ausdrucksvollen Form fand er die aus der Konstruktion sich ergebende als die ausdrucksvollste - oder: die Vernunft führt ihn zur Konstruktion, und das Gefühl deutet die Konstruktion.

Charakteristisch eine weitere Stelle aus van de Velde Erläuterung des Folkwang-Museums:
Ich suchte lange nach einer Lösung für das Geländer, die mir durch den Zuschnitt der Stufen bedeutend erschwert wurde. Als ich gefunden hatte, in welcher Art jedem Tritt eine schmiedeeiserne Geländerdocke angebracht werden sollte (diese greift mittels einer flachen Lasche unter das Stufenprofil und ist dort angebolzt, während zwei Seitenarme dieser Geländerdocke, die auf der Trittfläche ruhen, hufeisenförmig nach oben streben), schien sie mir so klar und einfach, daß ich mich beinahe schämte, so lange über eine solche Sache nachgedacht zu haben.

Schon seine frühen Räume für Bings L'Art Nouveau, Paris (1897), noch durchaus Jugendstil, entzückten durch ihre funktionale Geschmeidigkeit einen Goncourt, der in seiner Kritik das treffende Wort "Yachting Style” prägte. (Osthaus, S.18).

Van de Veldes Stellung zur Technik, zur Konstruktion ist demnach eine ästhetische, wie auch seine Maschinenbegeisterung kein Widerspruch zur Einfühlung ist. Auch die Maschine sieht van de Velde formal-ästhetisch an. Denn ihre Konsequenzen lehnt er erbittert ab. Während Peter Behrens die Maschine ziemlich kühl als pseudo-ästhetisches Gebilde definiert, ist van de Velde der erste Vertreter eines romantischen Maschinenkults, der viele Nachfolger gefunden hat.

Maschine: das ist Normun g, Typisierung, Kollektivismus - van de Velde aber ist leidenschaftlicher Individualist! Bei der Kölner Werkbundtagung (1914) war er der Führer der "Künstler”', Gruppe gegen Muthesius' Typenvorschläge. Er erklärte: "Der Küns 
tler ist seiner inner' sten Essenz nach glühender Individualist -aus freien Stücken wird er niemals einer Disziplin sich unterwerfen, die inm einen Typ aufzwingt." Eine Wandlung deutet der Aufsatz "Devant l'architecture" an, aus dem ein tiefes Verständnis für die kollektiven Bauaufgaben unserer Zeit und ein schönes Vertrauen in die Arbeit der jungen Generation aller Länder spricht. (Europe, 15.7.24).

Freier von Vorstellungen einer historisch, monumentalen Form als Behrens schmiegte sich van de Velde offener der Bewegung alles Lebendigen an und entwickelte so eine von der Funktion her bestimmte, dynamische, von inm selbst gern als "dramatisch" bezeichnete, $d$. $h$. eine weniger historische, eine werdende Form, die einen ingenieur-und konstrukteur-haften Charakter aufwies. -Aufschlußreich der Vergleich eines van de Veldeschen Gerätes etwa mit Peter Behrensschen AEG Lampen. Van de Velde sucht den einheitlichen Schwung der Bewegung aus der Erfühlung und Erfüllung der Funktionen des Stehens, Steigens, Greifens, Tragens usw. Er sagt mehrfach von seinen Formen: "Ich offenbare ihr Innerstes, ihre Seele." - Peter Behrens, Wright näherstehend, kontrastiert einfache stereometrische Grundformen. -Dort Temperament, hier Distanz.

Den starken Einfluß van de Veldes auf die jüngere europäische Architektenschaft zeigt unter anderem sehr deutlich Erich Mendelsohns (geb. 1887) Einstein-Turm bei Potsdam (1920/21). Auch ein gewis- ser Einschlag Olbrichs (frühe Darmstädter Ausstellungsbauten) ist bei Mendel' sohn zu spüren. Frühe Skizzen zum Einstein,Turm (etwa das Titelblatt (1919) des Wendingenheftes) belegen, wie sehr auch Finsterlin inm damals nahestand. Man vergleiche z. B. die Finsterlin-Blätter 11 oder 14 seiner Wendingen-Publikation mit der angegebenen Zeichnung Mendelsohns. Freilich ist stets die dekorative Selbstgenügsamkeit Finsterlins bei Mendelsohn in ingenieurhafte Energie und Spannung verwandelt. "Übrigens ist es sehr charakteristisch, daß es das Blatt der zur Romantik neigenden Amsterdamer Richtung in Holland ist (de Klerk [t 1923], van der Mei, Kropholler, Wijdeveld u. a.), welches diesen beiden Deutschen: Mendelsohn und Finsterlin, Sonderhefte widmete.

Der Wunsch nach zugespitzter Charakterisierung und ausdrucksvoller Individualisierung führt Mendelsohn bei seinem Einstein-Turm und auch - weniger betont - bei seinem Mosse-Aufbau (Berlin, 1921 bis 1923) zu einer stark mit Bewegungen und Anthropomorphismen arbeitenden Architektur, die man wirklich als eine "dramatische" im Sinne van de Veldes bezeichnen kann und die durchaus innerhalb der Bewegung des Expressionismus zu verstehen ist. Der Eingang "saugt", die Wände "führen", die Treppenstufen "schwingen" usw. (Vom Mosse Haus: “... kein unbeteiligter Zuschauer der sausenden Autos, des hin und herflutenden Verkehrs, sondern es ist zum aufnehmenden, mitwirkenden Bewegungselement geworden.") Aus einer verwandten Einstellung 
resultierte der Ausstellungsraum, den Richard Döcker - Stuttgart (1921) für eine Werkbundausstellung durchgeführt hat, während gewisse frühe Arbeiten von Hans und Wassili Luckhardt die besondere Nuance eines Novembergruppen-Expressionismus hatten, über den sie sich mit der Fabrik "Norma" und der Garage "Wender"' bald hinaus entwickelten. Auch für Döcker war jener Raum nur ein Übergang.

Der Einstein-Turm gehört durch die Zugespitztheit seiner Charakteristik in die Reihe: Wertheim-BauTurbinenhalle, und durchaus zutreffend sagt der holländische Architekt J. F. Staal in einer Kritik des Turmes: er sei mehr Denkmal als Werkstatt: "Het is het beste Duitsche, het behoort tot het beste persoonlijke werk, maar het is nog Duitsch en nog persoonlijk." (Wendingen, Oktober 1920.)

Sachlicher, objektiver sind einige Entwürfe Mendelsohns für industrielle Zwecke, die nun zum ersten Male den Gewinn der ganzen Arbeit zeigen. Hier erst - wenn wir immer absehen von den amerikanischen Ingenieurbauten - ist der Typ des "Hauses": senkrechte Wände, Dach, Fenster - völlig überwunden zugunsten des Begriffes: geformter Raum, ist von innen her überwunden, nicht nur von außen her verdeckt durch Pathos und Stilisierung. Was hier notwendig und von innen heraus zum Bruch mit dem alten Typus führte, war die konsequente Ausnutzung des Eisenbinders. In seinem Vortrage "Problem einer neuen Baukunst" (1919) betont Mendelsohn, wie mit dem Auftreten des Eisenbinders ein neues Kapitel der Baugeschichte beginne:

Aus Säule und Marmorbalken des griechischen Tempels; aus Pfeiler' und Steingewölbe des gotischen Doms wird die Binderschwingung eiserner Hallen. Nach dem Lastausgleich der Antike; nach der Lastaufhebung des Mittelalters entsteht die dynamische Spannung der Eisenbetonkonstruktion. (Wasmuths Monatshefte 1924, S.3.)

Überzeugend wirkt bereits das Modell einer optischen Fabrik 1919. Hier und in dem Bau der Hutfabrik Luckenwalde 1921-23 ist aus der zweckmäßigsten Organisierung des Produktionsganges die nächste, engst anliegende Raumgestalt entwickelt, eine Gestalt, die den Funktionen des Betriebes, dem Produktionslauf, so unmittelbar folgen und entsprechen soll, wie es die Glieder einer Maschine tun. Im Umbau der Wüstegiers' dorfer Textilwerke (1922/23) und besonders in der mit Richard Neutra verfaßten Wettbewerbsarbeit für das Geschäftszentrum von Haifa (1923) kam Mendelsohn zu einer erfreulichen Einfachheit und Ruhe.

\section{Não mais edifício, mas espaço conformado}

Já havíamos falado sobre o elemento "movimento" em Wright. Para Van de Velde, ele age como algo muito diferente. A diferença é aquela entre um americano objetivo e um europeu romântico; então Van de Velde é, além de racionalista, um romântico. 
2. Haus, casa, foi traduzido por nós como "edifício", seguindo a sugestão da tradução para o espanhol de Josep Giner i Olcina.
O movimento, para Wright, é um embate consequente e consciente do espaço - na planta - e uma enérgica relação de tensão entre os elementos construtivos - em elevação. Os componentes construtivos em si são totalmente "inexpressivos", são mesmo imóveis, peças estáticas tecnicamente determinadas, susceptíveis à normalização. O movimento atua como uma força mecânica vinda de fora (externa). A vontade humana, com a ajuda da máquina, construiu a casa em ângulos vivos a partir de peças acabadas e ortogonais.

Van de Velde toma o movimento em um sentido literal, como uma força que organiza a construção a partir do interior. Obtém curvas e vibrações, formas que só podem ter vigência uma única vez, que somente em seu contexto podem resultar válidas. Ele fala de formas eloquentes e expressivas. A simples vontade humana, percebida como limitada, não deveria determinar e estabelecer uma obra, mas sim a vontade da objetividade, da função, dos materiais, que deveria propriamente estabelecer-se a si mesma, em um processo no qual o ser humano não é mais que um mediador. Van de Velde exercita uma empatia com a função e atinge a expressão formal do movimento, o que por Wright é absolutamente evitado. A concepção de Van de Velde é paralela ao expressionismo pictórico, aparecido mais tardiamente. Função - movimento - expressão contínua - simbolismo - romantismo - individualismo - e, finalmente, antropomorfismo -, mantêm uma proximidade lógica, o que significa que a in- fluência de Van de Velde foi importante e valiosa, mas não totalmente inofensiva. Ela também continha um perigo.

Na concepção de Wright, o tipo "edifício" poderia perdurar, apesar de todas as inovações e melhorias. A singularidade, clareza e firmeza do contorno delimitavam espaços que a vontade humana havia ordenado e submetido.

Na visão de Van de Velde, os limites se confundem. O resultado da liberação de forças que se manifestam em potentes curvas e balanços pôde muito bem quebrar a caixa e fazer com que um tipo completamente diferente, um organismo livre, ocupasse seu lugar. Um exemplo em pequeno tamanho: a escrivaninha da casa Hohenhof, em Osthaus.

As casas de Van de Velde (Esche e Körner em Chemnitz, Hohenhof e Springmann em Hagen in Westfalen, Dürckheim e Henneberg em Weimar e Schulenburg em Gera) não revelam a dissolução do tipo "edifício"2- muito provavelmente também a casa do médico Dr. Leuring em Scheveningen - porque o romântico Van de Velde é, ao mesmo tempo, um construtor. Como tal, ele abandona o tipo "edifício" apenas onde é objetivamente necessário - ao construir a Escola de Arte de Weimar ou o Teatro do Werkbund em Colônia, que infelizmente foi demolido sem motivo aparente. Estas duas construções mostram quão valiosa pode ser a concepção do movimento no sentido de Van de Velde para 
uma renovação da estrutura do edifício - apesar de algumas reverberações do Art Nouveau que ainda existem aqui.

Se quisermos ver com clareza a consequência final de um funcionalismo romântico-panteísta, o melhor é prestar atenção aos projetos de Hermann Finsterlin - a dissolução mais radical possível do conceito de "edifício" e a abordagem da casa em formas orgânicas, da natureza em crescimento.

O tipo formal da última grande invenção do Espírito da Terra, a forma do orgânico, situa-se entre o cristal e o amorfo. Desse caminho intermediário também brota minha arquitetura. No interior da nova casa, o homem não apenas se sentirá como um ocupante de uma fabulosa câmara de cristal, mas também como habitante interno de um organismo, vagando de órgão em órgão, um simbionte em troca com um gigantesco útero fossilizado. Um pequeno fragmento do conjunto de caixas translacionais das formas do mundo está presente na sequência cidade, casa, móveis, vasilhas; crescendo um do outro como as gônadas de um organismo, essas criaturas vazias não precisam ser alocadas como corpos estranhos entre si. Diga-me se o esquema violento de suas seis paredes, caixão injetado de suas mil necessidades, nunca o irritou se um desejo misterioso nunca chegou a você, para reorganizar o espaço de acordo com o ritmo com que respira sua alma? (Frühlicht, Edição 2, p. 36).

Finsterlin, que chama seus projetos de "sistemas de moinhos glaciais da alma", é um romântico de- senfreado. Mas Van de Velde não é apenas romântico, ele também é um racionalista. Assim como Finsterlin, o Van de Velde romântico pouco pertence a um gênero do passado, e o racionalista é, com ênfase, um homem do nosso tempo.

Nada é feio no mundo das invenções técnicas, da máquina e dos mil utensílios que servem a propósitos importantes, como na arquitetura, nas artes e nos ofícios. Sim, suas formas, marcadas pela verdade e ousadia, encantaram a todos aqueles que esperavam apaixonadamente a nova beleza futura, e despertaram a maior admiração." (Os três pecados contra a beleza, p. 41.)

O que parece incomodar, para quem luta contra esses princípios, além do fato de serem princípios, é o de também exigirem um esforço mental ao qual não estão mais acostumados... Estamos no fim do mundo, ou em algum beco sem saída do puritanismo mais árido, para que nos remetamos a regras fáceis de construção formal, através das quais descobriremos o caráter secreto de nossa época vazia em que, depois de se ter verificado tudo, só se está satisfeito com as coisas - não importa em que área - que, depois de examinadas, nos pareçam apenas as mais sensatas, poderosas e aptas a produzir coisas ainda mais sensatas e poderosas? (Innerdekoration, nov. 1902).

Entre o Van de Velde romântico e o racionalista, estende-se uma ponte - a construção. Van de Velde explica a forma de sua coluna no vestíbulo do Museu Folkwang dizendo, em resumo: "Sua forma mostra sua alma ou, se você quiser ser mais preci- 
so, seus ossos." (Innerdekoration, out-nov. 1902). Procurando por formas expressivas, ele achou que aquela que resulta da construção era a mais expressiva - ou: a razão o levou à construção, e o sentimento a interpretou.

Outra passagem da explicação de Van de Velde sobre o Museu Folkwang é característica: "Durante muito tempo eu procurei uma solução para o corrimão que, cortado pelos degraus, estava significativamente dificultado. Quando eu encontrei a maneira pela qual um corrimão de ferro forjado deveria ser anexado a cada degrau (ele chega sob o perfil do degrau com uma aba plana e é aparafusado ali, enquanto dois braços laterais deste corrimão, que repousam na superfície do degrau, se lançam para cima como uma ferradura), pareceu-me tão óbvia e simples que fiquei quase envergonhado de ter pensado nisso por tanto tempo." Até seus primeiros aposentos na boutique Bing L'Art Nouveau em Paris (1897), ainda bastante Art Nouveau, provocaram Goncourt com sua flexibilidade funcional que, em suas críticas, cunhou o apropriado termo "Estilo late" (Osthaus, p. 18).

A posição de Van de Velde sobre tecnologia e construção é, portanto, estética, de modo que seu entusiasmo por máquinas não contradiz a empatia. Van de Velde enxerga a máquina formal e esteticamente, e rejeita amargamente suas verdadeiras consequências. Enquanto Peter Behrens define friamente a máquina como uma entidade pseudoes tética. Van de Velde é o primeiro representante de um culto romântico à máquina, que encontrou muitos sucessores.

Máquina: ela é normatização, tipificação, coletivização - mas Van de Velde é um individualista apaixonado! No Congresso do Werkbund em Colônia (1914), Van de Velde conduziu o grupo dos "artistas" contra as propostas tipificadoras de Muthesius. Ele afirmou: "O artista é, por essência, um ardente individualista. Jamais se submeterá voluntariamente a uma disciplina que Ihe imponha um tipo". Seu ensaio "Devant l'architecture" sugere uma mudança significativa, que entrevê uma profunda compreensão das tarefas da construção coletiva de nosso tempo e uma boa confiança no trabalho das novas gerações de todos os países (Europe, 15.7.24).

Mais liberto do que Behrens da ideia de uma forma histórica e monumental, Van de Velde se concentrou abertamente no movimento de tudo o que vive, e desenvolveu, a partir da função, uma forma em evolução, segura e dinâmica, que ele próprio denominou "dramática", ou seja, menos histórica, uma forma em devir que mostrava o caráter da engenharia e do material. É reveladora a comparação entre um utensílio de Van de Velde, por exemplo, e as luminárias de Behrens para a AEG. Van de Velde procura o momento único do movimento na compreensão profunda do cumprimento das funções de levantar-se, subir, recolher, carregar, etc. Das formas, afirma reiteradamente que "revela suas entra- 
nhas, sua alma". Peter Behrens, tão próximo a Wright, propõe, em contraste, formas básicas, simples e estereométricas. Ali, o temperamento; aqui, a distância.

A Torre de Einstein em Potsdam (1920/21), de Eric Mendelsohn, mostra com especial clareza a forte influência de Van de Velde sobre o conjunto dos jovens arquitetos europeus. Também se percebe em Mendelsohn um certo impacto de Olbrich (dos primeiros edifícios da exposição em Darmstadt). Os esboços iniciais da Torre Einstein (por exemplo, na capa da Revista Wendingen, 1919) documentam quão próximo Mendelsohn também estava de Finsterlin naquela época. Pode-se comparar, por exemplo, as páginas 11 e 14 da publicação de Finsterlin na Wendingen com o mencionado desenho de Mendelsohn. É bem verdade que a autossuficiência decorativa de Finsterlin se transforma sempre, em Mendelsohn, em energia e tensão engenheirística. É certamente muito característico que a revista da Escola de Amsterdã, tão inclinada ao romantismo (de Klerk, van der Mey, Kropholler, Wijdveld e outros) tenha dedicado, na Holanda, números extraordinários a estes dois alemães: Mendelsohn e Finsterlin.

A aspiração a uma caracterização exagerada e a uma expressiva individualidade levou Mendelsohn em sua Torre Einstein, e também - em menor medida - no edifício Mosse (Berlin, 1921-1923) a uma arquitetura que manejava com força o movimento e o antropomorfismo, e que pode muito bem ser descrita como "dramática", no sentido de Van de Velde, devendo ser totalmente entendida dentro do movimento expressionista. A entrada "suga", as paredes "direcionam", os lances da escada "embalançam". O edifício Mosse "não é um espectador alheio aos veículos apressados, ao tempestuoso ir e vir do tráfego, mas chega a ser um elemento que absorve o movimento da rua e coopera com dele". A sala de exposições que Richard Döcker realizou em Stuttgart (1921) para uma exposição do Werkbund resultou de um enfoque análogo; e uma parte da obra inicial de Hans e Wassili Luckhardt mostrava nuances próprias de um expressionismo do Novembergruppe, do qual logo se afastaram com a fábrica "Norma" e a garagem "Wender"; também para Döcker, a sala de exposições representou um momento de transição.

A Torre Einstein pertence, pela caracterização exagerada de suas linhas, à sucessão Edifício Wertheim - Fábrica de Turbinas, e é razoável o que diz o arquiteto holandês J. F. Staal em uma crítica sobre a torre: se trata mais de um monumento que de um lugar de trabalho, "é o melhor da Alemanha, e é um dos melhores trabalhos pessoais, mas é demasiado alemão e demasiado pessoal" (Wendingen, outubro de 1920).

Mais objetivos são alguns projetos de Mendelsohn com finalidade industrial que, agora, mostram o saldo positivo de todo seu trabalho. Aqui, se prescindir- 
mos das construções da engenharia americana, pela primeira vez o tipo "edifício" - paredes verticais, cobertura, janelas - resulta completamente superado em favor do conceito de espaço conformado; resulta superado por dentro, não só escondido exteriormente mediante o pathos e a estilização. $O$ que aqui se constituiu enquanto necessidade e do interior para o exterior e que levou à ruptura com o velho tipo foi a exploração consequente da estrutura. Em sua conferencia "Problema de uma nova arte de construir" (1919), Mendelsohn sublinhou que, com a aparição do arrebite de ferro, se iniciava um novo capítulo da história da construção.

À coluna e ao dintel de mármore do templo grego, ao pilar e abóbada de pedra da catedral gótica, procede a estrutura ondulante das naves metálicas. Depois de equilibrada a estabilidade das cargas da Antigüidade, depois do erguimento das cargas na Idade Média, nasce a tensão dinâmica da construção em concreto armado. (Wasmuth, Monatshefte, 1924, p.3).

O exemplo da Fábrica de Óculos de 1919 já produziu um efeito convincente. Aqui, e na construção da Fábrica de Chapéus em Luckenwalde (19211923), sempre a partir da organização mais apropriada do processo da produção, se obtém a configuração espacial mais ajustada, uma configuração que segue tão de perto as funções do estabelecimento e corresponde em tamanha conformidade ao curso da produção como as peças de uma quina. Em uma intervenção na fábrica têxtil de
Wüstegiersdorf (1922-23) e, especialmente, no projeto do concurso preparado com Richard Neutra para o Centro Comercial de Haifa (1923), Mendelsohn conseguiu uma simplicidade e uma serenidade muito satisfatórias.

\section{Referências}

BEHNE, A. 1923. La construcción funcional moderna. Edição e prefácio de José Ángel Sans Esquide. Tradução de Josep Giner i Olcina. Barcelona: Colegio de Arquitectos de Cataluña y Ediciones Serbal, 1994.

BEHNE, A. Der Moderne Zweckbau. Berlin: Gebr. Mann Verlag, sd.

COLQUHOUN. A. Modernidade e tradição clássica. Ensaios sobre arquitetura. São Paulo: Cosac\&Naify, 2004.

FRAMPTON, K. História crítica da arquitetura moderna. São Paulo: Martins Fontes, 2008. 